\title{
Evaluation of Green Economic Development Abilities of Hubei Province in 2008-2018
}

\author{
Tian Zhang, Yuanying Chi* \\ School of Economics and Management, Beijing University of Technology, Beijing 100124, China
}

Corresponding Author Email: goodcyy@bjut.edu.cn

https://doi.org/10.18280/ijsdp.150607

Received: 8 February 2020

Accepted: 10 June 2020

\section{Keywords:}

green economy, entropy method, index system, resource and environment carrying capacity (RECC)

\begin{abstract}
The green economic development ability (GEDA) is crucial to long-term sustainable development. Based on the relevant data from 2008 to 2018, this paper sets up an evaluation index system of the GEDA, and uses the entropy method to evaluate and analyze the GEDAs of central China's Hubei Province in the sample period. The results show that the GEDA of Hubei Province improved significantly in the 11 years from 2008 to 2018; the resource and environment carrying capacity (RECC) contributed the greatest to the GEDA improvement, followed by economic greenness and policy support. However, the RECC index had clear oscillations in the sample period. As a result, Hubei Province should further strengthen the protection of resources and ecology, and raise concerns about the environment and climate change.
\end{abstract}

\section{INTRODUCTION}

In 1989, the concept of green economy was first proposed [1]. Since the 19th National Congress of the Communist Party of China in 2017, the concept of green development has been implemented in China while vigorously promoting the construction of ecological civilization. The conviction that lucid waters and lush mountains are invaluable assets has been deeply rooted in the hearts of the people. Also, the European Union adopted a new strategy for economic growth in 2019 and emphasized the importance of the concept of green economy [2]. Scholars from all over the world have carried out extensive research on green economy, and proposed that the development of green economy is an inherent requirement for sustainable development and a necessary condition for human well-being [3-6]. It is emphasized that the concept of sustainable development should be combined with economic development models to deal with environmental degradation and resource depletion [7, 8]. Therefore, it's of great significance to study the evaluation of the GEDA. A complete, scientific, and rigorous evaluation system is needed to effectively monitor the development of green economy.

In recent years, scholars around the world have conducted research on the relationship between different influencing factors and the GEDA. Mariú Abritta Moro used National Innovation Capability (NIC) as an analytical framework to study the impact of water resources on the development of green economy, and proposed that the water supply sector can improve the economic sustainability by efficiency improvement [9]. Through technical and economic analysis, Meltem Ucal established a multi-directional relationship between climate change, energy use and economic sustainability, and launched a green economy development strategy [10]. Hoang Phong Le evaluated the impact of fossil energy consumption on environmental sustainability and put forward policy recommendations of green development to reduce $\mathrm{CO}_{2}$ emissions [11]. From the perspective of renewable energy technology development, Fangming Xie presented that the improvement of renewable energy use technology can effectively coordinate the relationship between energy consumption and sustainable economic development [12]. Lilia Matraeva revealed the significant improvement space for the sustainability of economic development through energy efficiency, and given the improvement direction of energy efficiency policies [13]. In addition, some scholars have explored the influencing factors of the GEDA comprehensively from the aspects of the construction sector, tourism, carbon dioxide emissions, and urban green spaces [14-17]. However, in view of different influencing factors, there have been few studies on the integration of these factors [18]. Therefore, different scholars have successively established evaluation systems for the GEDA on the countrylevel, rather than the regional GEDA $[19,20]$. Some others selected the green GDP [21], green economic efficiency [22], and green productivity index [23] for GEDA evaluation only at the macro level, which is not conducive to in-depth study of the mechanism between influencing factors. As above, great achievements have been made on green economy, but few studies were performed on the evaluation of the GEDA in certain region on a provincial basis.

Hubei Province enjoys a good industrial base, rich resource, and great development potential among the central provinces of China. It has an important strategic position in the overall pattern of our country's national economic development [24]. The construction of the GEDA evaluation system is conductive to exploring the advantages and disadvantages of the green development in Hubei Province, and to proposing targeted recommendations based on the research results. In previous literatures, the entropy method was selected to evaluate the GEDA of Hubei Province, but the data used was relatively old. Therefore, this paper attempts to analyze the status quo of Hubei Province's GEDA based on the data from 2008 to 2018, and proposes corresponding measures to improve its GEDA. 
This paper consists of five parts. The first part gives the introduction; the second part introduces index selection and data sources; the third part elaborates on research methods; the fourth part discusses empirical results and analysis; the last part makes conclusions and recommendations.

\section{INDEX SELECTION AND DATA SOURCES}

\subsection{Construction of the evaluation index system}

The green economy is an economic development model under the RECC constraints and government policy support, aiming at ecological environment protection and economic development. Thus, drawing on the Research on China Green Development Index compiled by Beijing Normal University etc., the authors constructed the evaluation index system of Hubei province's GEDA from the three dimensions of economic greenness, RECC, and government policy support based on the index selection principles of completeness, scientificity, comparability, practicality, and data availability. It includes 3 primary indices, 7 secondary indices, and 30 third-level indices, as shown in the Table 1.

Table 1. Evaluation system of green economy development ability

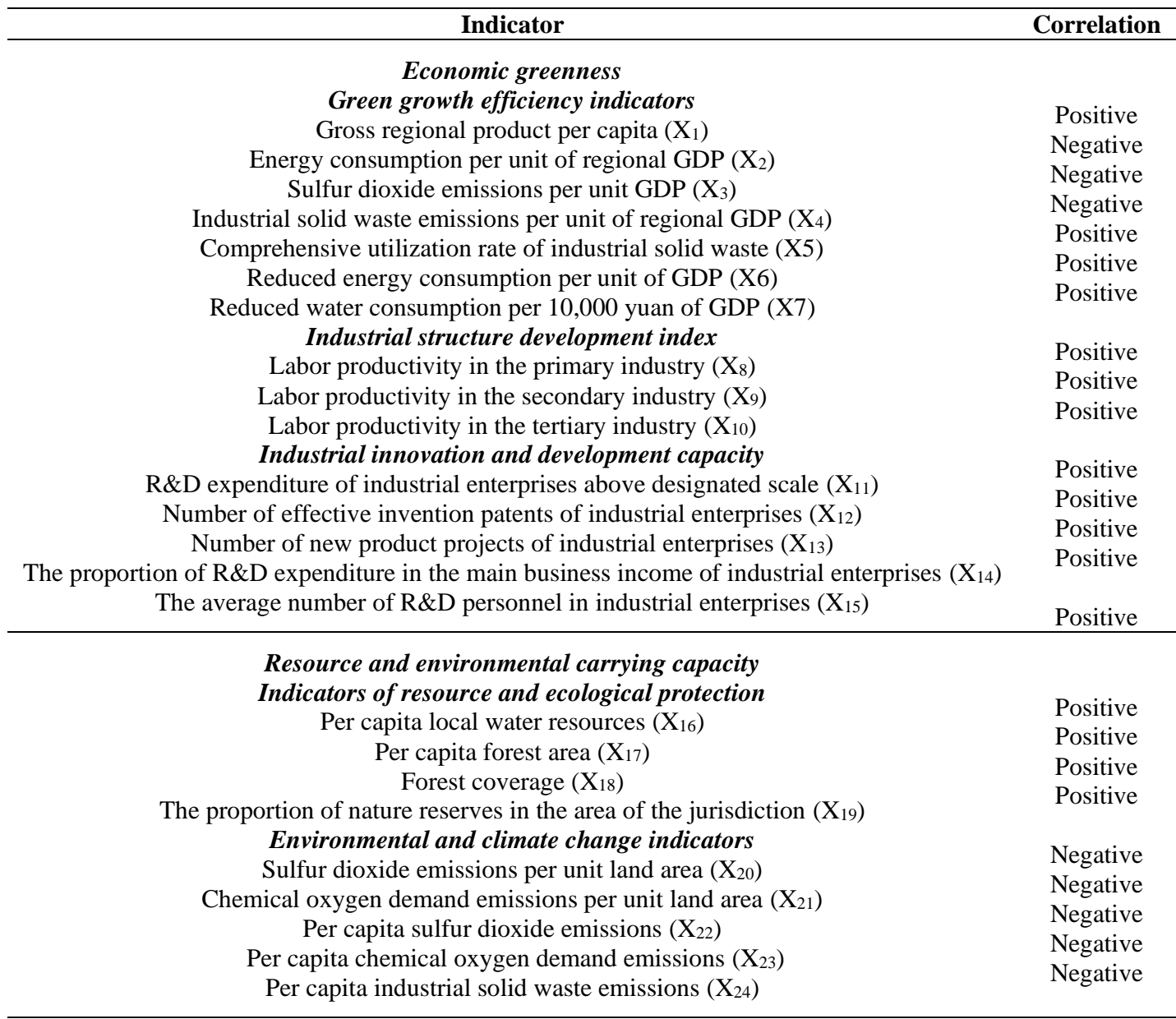

\section{Government policy support}

Government green investment indicators

The proportion of environmental protection expenditure in fiscal expenditure $\left(\mathrm{X}_{25}\right)$

The proportion of science, education, culture and health expenditure in fiscal expenditure $\left(\mathrm{X}_{26}\right)$

Infrastructure and urban management indicators

Urban green area per capita $\left(\mathrm{X}_{27}\right)$

Urban water popularizing rate $\left(\mathrm{X}_{28}\right)$

Urban sewage daily treatment capacity $\left(\mathrm{X}_{29}\right)$

Public transport vehicles per 10,000 people $\left(\mathrm{X}_{30}\right)$
Positive

Positive

Positive

Positive

Positive

Positive

\subsection{Index interpretation}

\subsubsection{Economic greenness}

The economic greenness is the actual state of green development, reflecting the impact degree of economic growth on resource consumption and environment, as well as the degree of innovation in the development of green economy. It includes three secondary indices. The green economic growth efficiency index reflect the degree of economic growth in the region; the degree of economic growth is characterized by per capita GDP; the impact degree of economic growth on the environment is measured by energy consumption per unit of regional GDP, sulfur dioxide emissions, industrial solid waste emissions per unit of regional GDP, comprehensive utilization rate of industrial solid waste, reduced energy consumption per unit of GDP, and reduced water consumption per 10,000 yuan 
of GDP. The other two indices of structure development and industrial innovation and development capabilities reflect the greenness of regional economies in the future, that is, the potential for economic greenness through industrial production efficiency and industrial technological innovation. Industrial structure development index is measured by labor productivity in the primary, secondary and tertiary industries; industrial innovation and development capabilities are reflected by the $R \& D$ expenditures of industrial enterprises above designated size, the number of effective invention patents of industrial enterprises above designated size, the number of new product projects of industrial enterprises above designated size, the proportion of $R \& D$ expenditures in main business income and the average number of R\&D personnel in industrial enterprises above designated size.

\subsubsection{Resource and environmental carrying capacity}

The RECC reflects the pressure of green development, and the potential that natural resources and the environment can carry. It consists of two secondary indices: the resource and ecological protection, and environmental and climate change. The former reflects the actual situation of the resources and ecology in the region, including the third-level indices such as per capita local water resources, per capita forest area, forest coverage, and the proportion of natural reserves in the area of the jurisdiction; the latter index includes sulfur dioxide emissions per unit land area, chemical oxygen demand emissions per unit land area, per capita sulfur dioxide emissions, per capita chemical oxygen demand emissions, and per capita industrial solid waste emissions, reflecting the impact of waste, waste water and exhaust gas emissions on the environment and climate in the process of economic development.

\subsubsection{Government policy support}

The policy support reflects the government's response to the development of green economy, including two secondary indices, namely the government green investment, and infrastructure and urban management. The former index reflects the government's emphasis on the relationship between resources, environment, economic development mode and economic development; it's subdivided into the proportion of environmental protection expenditure in fiscal expenditure, and the proportion of science, education, culture, and health expenditure in fiscal expenditure; the latter reflect the government's level of construction for economic green development, which is mainly measured by urban green area per capita, urban water popularizing rate, urban sewage daily treatment capacity, and public transport vehicles per 10,000 people.

\subsection{Data source}

The data used in this paper were from the Hubei Statistical Yearbook from 2008 to 2018 and the website of the National Bureau of Statistics, of which most index data was from the original data in the yearbook, and the others were obtained through calculation and processing. Price indices were used to eliminate the impact of price factors in different years in this paper. With 2008 as the base year, the real GDP of each year was calculated to reflect the changes in product output by year.

\section{RESEARCH METHODS}

\subsection{The principle of entropy method}

Entropy is a thermodynamic term proposed by German physicist Clausius in 1865 to reflect the degree of disorder in the system. Then, Claude Shannon introduced it into the field of information theory, and proposed the concept of information entropy [25]. In information theory, entropy is a measure of the degree of disorder in the system, while information is a measure of the degree of order, which both are equal in the absolute value and opposite in the sign [26]. The concept of entropy has been widely used in research fields such as sustainable development evaluation and social economy. The entropy method is an objective weigh evaluation method. In an index data matrix $X=\{x i j\} m \times n$ composed of $n$ plans to be evaluated and $m$ evaluation indices, with the dispersion degree of the data increasing, the information entropy decreases, and the amount of information increases; then, the impact of this data on the comprehensive evaluation and the weights shall be greater; on the contrary, with a smaller difference between the values of the indices, the information entropy is larger, and the amount of information become less, resulting in a smaller impact on the evaluation results and weights [27]. The entropy method can avoid the subjective interference of human factors in the weight determination, and the calculation results are supported by objective data, which truthfully reflects the importance of each index, and provides a basis for constructing an evaluation index system.

\subsection{Calculation steps of entropy method}

The entropy method was used to evaluate the GEDA in the specific steps as follows:

(1) Perform dimensionless processing of index data

The indices in the GEDA evaluation system have different dimensions and units. To eliminate the incommensurability, this paper adopts the maximum and minimum method for dimensionless processing, that is, the maximum and minimum of the original values were mapped on the interval $[0,1]$ through a linear transformation of the original data:

Positive index:

$$
X_{i j}=\frac{x_{i i}-\min \left\{x_{i j}\right\}}{\max \left\{x_{i j}\right\}-\min \left\{x_{i j}\right\}},(i=1,2, \cdots, m), \quad(j=1,2, \cdots, n)
$$

Negative index:

$$
X_{i j}=\frac{\max \left\{x_{i j}\right\}-x_{i j}}{\max \left\{x_{i j}\right\}-\min \left\{x_{i j}\right\}},(i=1,2, \ldots, m), \quad(j=1,2, \cdots, n)
$$

(2) Determine the proportion of the index, and calculate the proportion $B i j$ of the $j$-th individual in the $i$-th index:

$$
B_{i j}=\frac{Y_{i j}}{\sum_{j=1}^{n} Y_{i j}}(i=1 \sim m, j=1 \sim n)
$$


(3) Calculate the entropy value of the index $i$,

$$
e_{i}=-k \sum_{j=1}^{n} B_{i j} \ln B_{i j}
$$

where, $k>0, k=\frac{1}{\ln n}, e_{i j} \in[0,1]$

(4) Calculate the credit entropy of the index $i: g_{i}=1-e i$

(5) Calculate the weights of indicators at all levels:

$$
w_{i}=\frac{g_{i}}{\sum_{i=1}^{m} g_{i}}
$$

(6) Calculate the index at all levels:

$$
\ln i=\sum_{j=1}^{n} w_{i} Y_{i j}
$$

\section{EMPIRICAL RESULTS AND ANALYSIS}

\subsection{Weights of evaluation indices for Hubei Province's GEDA}

The entropy method was adopted to process the 30 indices in the GEDA evaluation system. Then, the weight of each indicator was calculated based on the relevant data of Hubei Province from 2008 to 2018. The results are shown in Table 2.

It can be seen from Table 2 that among the primary indices, the RECC had the highest weight, reaching $43 \%$, followed by economic greenness for $33 \%$, and government policy support for $23 \%$, which indicates that RECC contributed the greatest to Hubei Province's GEDA. The secondary indices of the RECC include resources and ecological protection index, and environment and climate change index, accounting for 59\% and $41 \%$, respectively. Secondary indices of economic greenness include green growth efficiency index accounting for $39 \%$, industrial development structure for $33 \%$, and industrial innovation and development capabilities for $28 \%$. Secondary indices of government policy support include government green investment for $43 \%$, and infrastructure and urban management for $57 \%$. The three-level indices that had a higher weight in these secondary indices were: energy consumption reduction per unit of GDP $\left(\mathrm{X}_{6}\right)$, labor productivity of primary industry $\left(\mathrm{X}_{8}\right)$, the number of effective invention patents of industrial enterprises above designated size $\left(\mathrm{X}_{12}\right)$, and local water resources per capita $\left(\mathrm{X}_{16}\right)$, sulfur dioxide emissions per unit land area $\left(\mathrm{X}_{20}\right)$, the proportion of environmental protection expenditures in fiscal expenditures $\left(\mathrm{X}_{25}\right)$, and the daily urban sewage treatment capacity $\left(\mathrm{X}_{29}\right)$.

Table 2. Weights of green economy indices

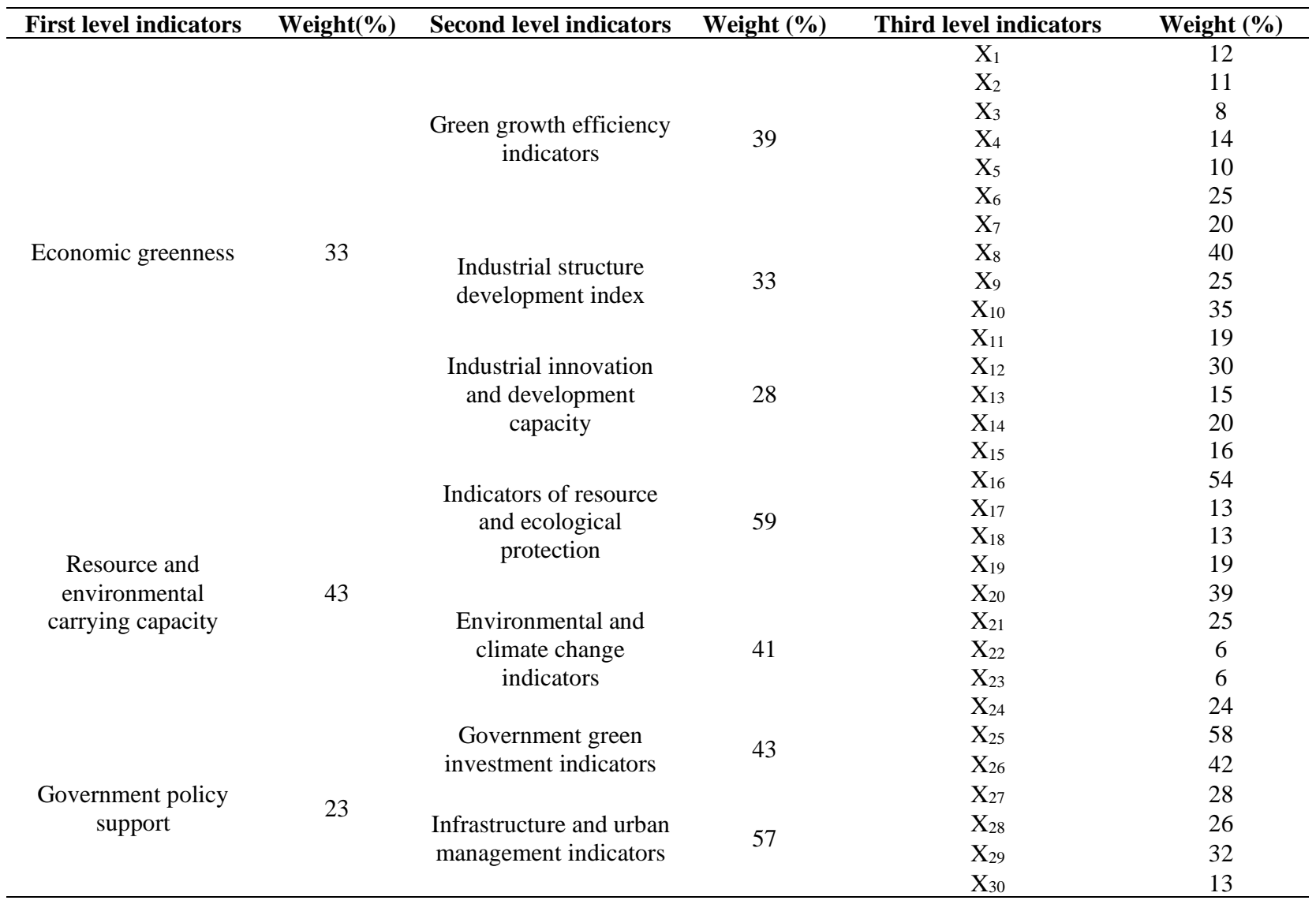




\subsection{Evaluation results of Hubei Province's GEDA}

As above, the 30 indices in the GEDA evaluation system were processed using the entropy method. And based on the relevant data of Hubei Province from 2008 to 2018, the GEDA of Hubei Province in the sample period was calculated. Table 3 and Figure 1 show the calculation results and variation trend.

It can be seen from Table 3 that the GEDA of Hubei Province has improved steadily and greatly in 11 years, from an index of 0.1207 in 2008 to 0.8904 in 2018. From Figure 1, the GEDA of Hubei Province declined three times in 11 years, namely in 2011 at the beginning of the Twelfth Five-Year period, 2013 during the implementation of the Twelfth FiveYear Plan, and 2017 at the beginning of the 13th Five-Year period. Among them, the decline of Hubei Province's GEDA in 2011 and 2017 was due to the reduction in the RECC, and the decline in 2013 resulted in the substantial reduction in the degree of economic greenness and government policy support.

The economic greenness has shown a steady upward trend, and achieved significant improvement in 11 years. The fall in 2013 also led to a reduction in the GEDA that year, mainly due to the substantial reduction in the green growth efficiency indicator. In 2013, Hubei promoted the construction of Hubei Province from five Perspectives for the first time. But it suffered a sharp economic downturn in the first quarter, and did not start to rebound until the third quarter. This resulted in a rising trend in energy consumption per unit of GDP, reflecting the development of the capacity utilization rate in some industries is still at a low level and the tertiary industry, especially the modern service industry, is underdeveloped. From 2015 to 2016, economic greenness achieved a substantial increase, mainly due to the increase in industrial development structural indicators. In 2016, Hubei Province successively introduced policies and measures for the development of a new economy and the transformation of traditional industries, and continuously implemented the "Ten Thousand Enterprises for Trillion Technological
Transformation Projects", which has optimized the industrial structure and greatly increased the labor productivity of various industries.

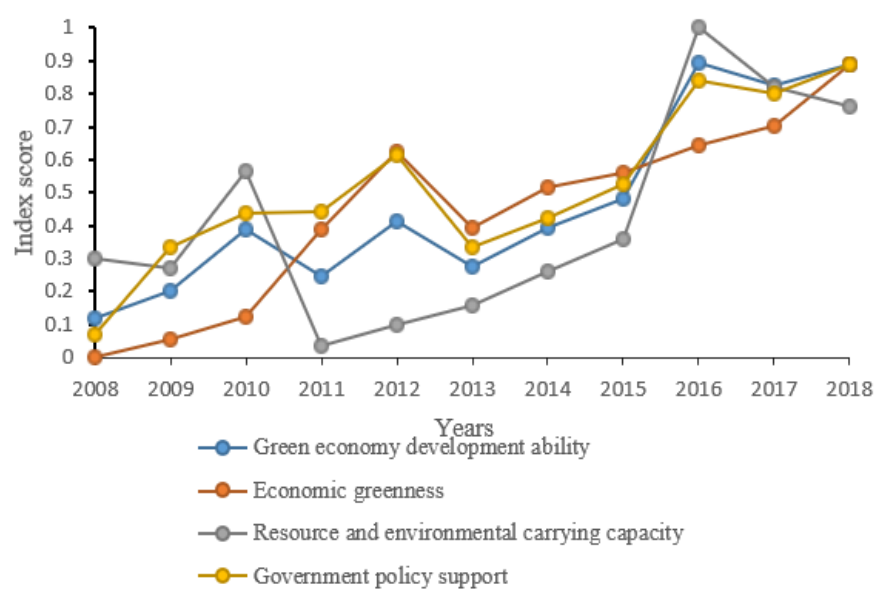

Figure 1. Historical changes in the evaluation indices of Hubei Province's green economy development ability

The RECC index has shown a clear ups and downs trend in 11 years. It dropped significantly in 2011 and 2017, leading to a decrease in the GEDA. In 2011, Hubei Province suffered severe natural disasters such as droughts and floods, which directly caused a significant reduction in the amount of water resources per capita. This not only significantly reduced the resources and ecological protection indicators, but also revealed the insufficient agricultural ability to resist natural disasters. In 2017, the amount of water resources per capita in Hubei Province decreased slightly. Despite the implementation of River Chief System and Lake Chief System, the resource and ecological protection index fell, because the drinking water source protection system proposed for the first year didn’t produce a significant effect.

Table 3. Evaluation results of green economy development ability in Hubei Province

\begin{tabular}{|c|c|c|c|c|}
\hline Year & $\begin{array}{l}\text { Economic } \\
\text { greenness }\end{array}$ & $\begin{array}{c}\text { Resource and environmental carrying } \\
\text { capacity }\end{array}$ & $\begin{array}{c}\text { Government policy } \\
\text { support }\end{array}$ & $\begin{array}{c}\text { Green economy development } \\
\text { capacity }\end{array}$ \\
\hline \multirow{2}{*}{2008} & 0.0000 & 0.2991 & 0.0709 & 0.1207 \\
\hline & $(11,3)$ & $(6,1)$ & $(11,2)$ & $(11)$ \\
\hline \multirow{2}{*}{2009} & 0.0531 & 0.2699 & 0.3344 & 0.2013 \\
\hline & $(10,3)$ & $(7,2)$ & $(9,1)$ & (10) \\
\hline \multirow{2}{*}{2010} & 0.1236 & 0.5644 & 0.4386 & 0.3909 \\
\hline & $(9,3)$ & $(4,1)$ & $(7,2)$ & (7) \\
\hline \multirow{2}{*}{2011} & 0.3879 & 0.0341 & 0.4431 & 0.2482 \\
\hline & $(8,2)$ & $(11,3)$ & $(6,1)$ & (9) \\
\hline \multirow{2}{*}{2012} & 0.6230 & 0.1002 & 0.6120 & 0.4128 \\
\hline & $(4,1)$ & $(10,3)$ & $(4,2)$ & (5) \\
\hline \multirow{2}{*}{2013} & 0.3933 & 0.1576 & 0.3343 & 0.2758 \\
\hline & $(7,1)$ & $(9,3)$ & $(10,2)$ & (8) \\
\hline \multirow{2}{*}{2014} & 0.5150 & 0.2595 & 0.4215 & 0.3918 \\
\hline & $(6,1)$ & $(8,3)$ & $(8,2)$ & (6) \\
\hline \multirow{2}{*}{2015} & 0.5592 & 0.3615 & 0.5272 & 0.4843 \\
\hline & $(5,1)$ & $(5,3)$ & $(5,2)$ & (4) \\
\hline \multirow{2}{*}{2016} & 0.6445 & 1 & 0.8397 & 0.8948 \\
\hline & $(3,2)$ & $(1,1)$ & $(2,1)$ & (1) \\
\hline \multirow{2}{*}{2017} & 0.7048 & 0.8210 & 0.7987 & 0.8239 \\
\hline & $(2,3)$ & $(2,1)$ & $(3,2)$ & (3) \\
\hline \multirow{2}{*}{2018} & 0.8898 & 0.7596 & 0.8914 & 0.8904 \\
\hline & $(1,2)$ & $(3,3)$ & $(1,1)$ & (2) \\
\hline
\end{tabular}

Note: The first number in parentheses indicates the vertical ranking, the second number indicates the horizontal ranking (not including evaluation results), and the last column only shows the vertical ranking. 
The government policy support index has shown a steady upward trend, and achieved a significant improvement in 11 years. The fall in 2013 also led to a reduction in the GEDA that year, which is mainly due to the reduction of government green investment indicators. Hubei Province faced an economic downturn in the early stage of 2013. In the later period, the economic uptrend was not well founded and there was still greater downward pressure, resulting in a decrease in the proportion of environmental protection expenditures in fiscal expenditures.

\section{CONCLUSIONS AND RECOMMENDATIONS}

(1) Hubei Province's GEDA has improved significantly, from 0.1207 in 2008 to 0.8904 in 2018 . This indicates that Hubei province has focused more on improving its own GEDA while developing the economy steadily. However, in view of the existing fluctuations, a long-term mechanism of the green economy should be established as soon as possible to enhance the internal driving force.

(2) The change in the RECC is the key reason for the fluctuations in the GEDA of Hubei Province, so it's necessary to strengthen the sustainability of resources and environment. Hubei Province should restore the ecological environment of the Yangtze River, promote regional governance of key river basins, and strengthen water source protection. Also, considering the major impact of the natural disasters that have occurred in the past 11 years on the local water resources, it should focus on improving the ability of agriculture to resist natural disasters. Meanwhile, the joint prevention and control of waste gas in the region should be enhanced to reduce the discharge of pollutants, and make the greatest contribution to green development capabilities.

(3) The economic greenness and government policy support should be further consolidated. In terms of economic greenness, Hubei Province, on the premise of promoting steady economic growth, should improve the efficiency of economic growth, strengthen the integration of advanced manufacturing and service industries, and transform the industrial structure while improving the production efficiency of various industries. In addition, it should also make greater efforts to enhance its scientific and technological innovation capabilities, construct major scientific and technological platforms to exert the main role of Hubei's enterprise innovation, and focus on the cultivation of scientific research and innovative talents, thereby consolidating the high level of economic greenness. In terms of government policy support, Hubei Province should continue to maintain the proportion of fiscal expenditures on environmental protection, science, education, culture, and health, focus on urban construction, and further improve the level of urban greening and public transportation in the province.

\section{REFERENCES}

[1] Turner, R.K. (1990). Report on reports: Blueprint for a green economy. Environment: Science and Policy for Sustainable Development, 32(5): 25-26. https://doi.org/10.1080/00139157.1990.9929030

[2] Smol, M., Marcinek, P., Duda, J., Szołdrowska, D. (2020). Importance of sustainable mineral resource management in implementing the circular economy $(\mathrm{CE})$ model and the European green deal strategy. Resources, 9(5): 55. https://doi.org/10.3390/RESOURCES9050055

[3] Faivre, N., Fritz, M., Freitas, T., de Boissezon, B., Vandewoestijne, S. (2017). Nature-based solutions in the EU: Innovating with nature to address social, economic and environmental challenges. Environmental Research, 159:

509-518. https://doi.org/10.1016/j.envres.2017.08.032

[4] Cheng, Z., Li, L., Liu, J. (2020). Natural resource abundance, resource industry dependence and economic green growth in China. Resources Policy, 68: 101734. https://doi.org/10.1016/j.resourpol.2020.101734

[5] Khodaparast Shirazi, J., Mohamad Taghvaee, V., Nasiri, M., Assari Arani, A. (2020). Sustainable development and openness in oil-exporting countries: Green growth and brown growth. Journal of Economic Structures, 9: 119. https://doi.org/10.1186/s40008-020-00216-2

[6] Bilgaev, A., Dong, S., Li, F., Cheng, H., Sadykova, E., Mikheeva, A. (2020). Assessment of the current ecosocio-economic situation of the Baikal region (Russia) from the perspective of the green economy development. Sustainability, 12(9): 3767. https://doi.org/10.3390/su12093767

[7] D'amato, D., Droste, N., Winkler, K.J., Toppinen, A. (2019). Thinking green, circular or bio: Eliciting researchers' perspectives on a sustainable economy with Q method. Journal of Cleaner Production, 230: 460-476. https://doi.org/10.1016/j.jclepro.2019.05.099

[8] Merino-Saum, A., Baldi, M.G., Gunderson, I., Oberle, B. (2018). Articulating natural resources and sustainable development goals through green economy indicators: A systematic analysis. Resources, Conservation and Recycling, 139: 90-103. https://doi.org/10.1016/j.resconrec.2018.07.007

[9] Moro, M.A., Andersen, M.M., Smets, B.F., McKnight, U.S. (2019). National innovative capacity in the water sector: A comparison between China and Europe. Journal of Cleaner Production, 210: 325-342. https://doi.org/10.1016/j.jclepro.2018.10.329

[10] Ucal, M., Xydis, G. (2020). Multidirectional Relationship between Energy Resources, Climate Changes and Sustainable Development: Technoeconomic analysis. Sustainable Cities and Society, https://doi.org/10.1016/j.scs.2020.102210

[11] Le, H.P., Sarkodie, S.A. (2020). Dynamic linkage between renewable and conventional energy use, environmental quality and economic growth: Evidence from emerging market and developing economies. Energy Reports, 6: 965-973. https://doi.org/10.1016/j.egyr.2020.04.020

[12] Xie, F., Liu, Y., Guan, F., Wang, N. (2020). How to coordinate the relationship between renewable energy consumption and green economic development: from the perspective of technological advancement. Environmental Sciences Europe, 32(1): 1-15. https://doi.org/10.1186/s12302-020-00350-5

[13] Matraeva, L., Solodukha, P., Erokhin, S., Babenko, M. (2019). Improvement of Russian energy efficiency strategy within the framework of "green economy" concept (based on the analysis of experience of foreign countries). Energy Policy, 125: 478-486. https://doi.org/10.1016/j.enpol.2018.10.049

[14] Oberti, I., Plantamura, F. (2017). The inclusion of natural 
elements in building design: The role of green rating systems. International Journal of Sustainable Development and Planning, 12(2): 217-226. https://doi.org/10.2495/SDP-V12-N2-217-226

[15] Pan, S.Y., Gao, M.Y., Kim, H., Shah, K.J., Pei, S.L., Chiang, P.C. (2018). Advances and challenges in sustainable tourism toward a green economy. Science of the Total Environment, 635: 452-469. https://doi.org/10.1016/j.scitotenv.2018.04.134

[16] Pan, S.Y., Gao, M., Kim, H., Shah, K.J., Pei, S.L., Chiang, P.C. (2018). Advances and challenges in sustainable tourism toward a green economy. Science of the Total Environment, 635: 452-469. https://doi.org/10.1177/0144598719835591

[17] Zhu, Z., Lang, W., Tao, X., Feng, J., Liu, K. (2019). Exploring the quality of urban green spaces based on urban neighborhood green index - a case study of Guangzhou city. Sustainability, 11(19): 5507. https://doi.org/10.3390/su11195507

[18] Vukovic, N., Pobedinsky, V., Mityagin, S., Drozhzhin, A., Mingaleva, Z. (2019). A study on green economy indicators and modeling: Russian context. Sustainability, 11(17): 4629. https://doi.org/10.3390/su11174629

[19] Holger, S., Sandra, V., Jürgen-Friedrich, H. (2017). Green economy innovation index (GEII)-a normative innovation approach for Germany \& its FEW Nexus. Energy Procedia, 142: 2310-2316. https://doi.org/10.1016/j.egypro.2017.12.159

[20] Nahman, A., Mahumani, B.K., De Lange, W.J. (2016). Beyond GDP: Towards a green economy index. Development Southern Africa, 33(2): 215-233. https://doi.org/10.1080/0376835X.2015.1120649

[21] Stjepanović, S., Tomić, D., Škare, M. (2017). A new approach to measuring green GDP: A cross-country analysis. Entrepreneurship and Sustainability Issues, 4(4): 574-590. https://doi.org/10.9770/jesi.2017.4.4(13)
[22] Na, J.H., Choi, A.Y., Ji, J., Zhang, D. (2017). Environmental efficiency analysis of Chinese container ports with $\mathrm{CO}_{2}$ emissions: An inseparable input-output SBM model. Journal of Transport Geography, 65: 13-24. https://doi.org/10.1016/j.jtrangeo.2017.10.001

[23] Pan, W., Pan, W., Hu, C., Tu, H., Zhao, C., Yu, D., Zheng, G. (2019). Assessing the green economy in China: An improved framework. Journal of cleaner production, 209: 680-691. https://doi.org/10.1016/j.jclepro.2018.10.267

[24] Zha, J., He, L., Liu, Y., Shao, Y. (2019). Evaluation on development efficiency of low-carbon tourism economy: A case study of Hubei Province, China. Socio-Economic Planning Sciences, 66: 47-57. https://doi.org/10.1016/j.seps.2018.07.003

[25] Okon, I.B., Isonguyo, C.N., Antia, A.D., Ikot, A.N., Popoola, O.O. (2020). Fisher and Shannon information entropies for a noncentral inversely quadratic plus exponential Mie-type potential. Communications in Theoretical Physics, 72(6): 065104. https://doi.org/10.1088/1572-9494/ab7ec9

[26] Fedajev, A., Stanujkic, D., Karabašević, D., Brauers, W. K., Zavadskas, E.K. (2020). Assessment of progress towards "Europe 2020" strategy targets by using the MULTIMOORA method and the Shannon Entropy Index. Journal of Cleaner Production, 244: 118895. https://doi.org/10.1016/j.jclepro.2019.118895

[27] Karagiannis, R., Karagiannis, G. (2020). Constructing composite indicators with Shannon entropy: The case of Human Development Index. Socio-Economic Planning Sciences, $\quad 70: \quad 100701$. https://doi.org/10.1016/j.seps.2019.03.007

[28] Haghizadeh, A., Siahkamari, S., Haghiabi, A.H., Rahmati, O. (2017). Forecasting flood-prone areas using Shannon's entropy model. Journal of Earth System Science, 126(3): 39. https://doi.org/10.1007/s12040-0170819-x 